\title{
Understanding the Sociocultural Drivers of Urban Bushmeat Consumption for Behavior Change Interventions in Pointe Noire, Republic of Congo
}

\author{
Alexandre M. Chausson ${ }^{1,2}$ D $\cdot$ J. Marcus Rowcliffe ${ }^{2,3} \cdot$ Lucie Escouflaire $^{4} \cdot$ Michelle Wieland $^{4} \cdot$ Juliet H. Wright $^{2,3}$
}

Published online: 18 March 2019

(C) The Author(s) 2019

\begin{abstract}
Interventions targeting consumer behavior may help to reduce demand for bushmeat in urban areas. Understanding the drivers of urban bushmeat consumption is crucial to guide such interventions; however the cultural and socio-psychological factors driving consumer behavior remain understudied. Through qualitative interviews with urban bushmeat consumers in Pointe Noire, Republic of Congo, we investigated perceptions of bushmeat and other animal proteins, and social norms regulating urban demand for bushmeat. The perception of bushmeat as natural, tasty and healthy, and a rare luxury product functioning as a symbol of social status, underpins social norms to provide bushmeat. The main barriers to purchasing were cost and availability. Locally produced fish, meat, and poultry were positively perceived as organic and healthy, whereas frozen imported animal proteins were perceived negatively as transformed, of poor quality and taste, and unhealthy. Our findings provide an initial baseline understanding of social-psychological drivers shaping consumption that can inform the design of bushmeat demand reduction campaigns.
\end{abstract}

Keywords Central Africa - Perceptions - Social norms - Demand reduction - Behavior change urban bushmeat consumption, Pointe Noire

\section{Introduction}

Central Africa harbors the second largest extent of tropical rainforest in the world, and its integrity is essential for biodiversity and livelihoods (Somorin et al. 2012). Bushmeat

Electronic supplementary material The online version of this article (https://doi.org/10.1007/s10745-019-0061-z) contains supplementary material, which is available to authorized users.

Alexandre M. Chausson

alexandre.chausson@zoo.ox.ac.uk

1 Present address: Department of Zoology, University of Oxford, South Parks Road, Oxford OX1 3PS, UK

2 Imperial College London, Silwood Park Campus, Buckhurst Road, Ascot SL5 7PY, UK

3 Institute of Zoology, Zoological Society of London, Regent's Park, London NW1 4RY, UK

4 Wildlife Conservation Society, Africa Program, 2300 Southern Blvd, Bronx, NY 10460, USA hunting is considered a major threat to biodiversity (Nasi et al. 2011) with implications for ecosystem function (Effiom et al. 2013) and associated ecosystem services, such as carbon sequestration (Peres et al. 2016). Demand for bushmeat in urban areas in Central Africa plays a substantial role in driving bushmeat hunting and trade (de Merode and Cowlishaw 2006; van Vliet and Mbazza 2011), with urban populations consuming a substantial proportion of the total harvest in the Congo Basin. Yet wildlife depletion caused by overhunting can threaten the food and livelihood security of rural communities (Nasi et al. 2011). Bushmeat is a vital source of protein in many rural areas and reduced availability can have negative health and nutrition impacts (Golden et al. 2011).

Reduction of urban demand for bushmeat is therefore essential for biodiversity conservation and rural communities' wellbeing. In situations of ineffective regulations and weak law enforcement, interventions targeting consumer preferences offer a possible avenue to achieve such a reduction (Rowcliffe et al. 2004). However, to be effective, behavior change interventions must be grounded in an understanding of the sociocultural drivers underpinning consumer demand patterns. While previous studies have investigated economic factors 
driving bushmeat consumption (East et al. 2005; Wilkie et al. 2005), research on the cultural, social, and psychological dimensions of urban bushmeat demand is still lacking (van Vliet and Mbazza 2011; Randolph 2016). Although bushmeat consumption in rural areas is often driven by a lack of available and affordable alternatives, in urban centers, bushmeat can be more expensive than other animal proteins and is regarded as a luxury item (Cowlishaw et al. 2005; Shairp et al. 2016). Research has shown bushmeat consumption to be influenced by taste preferences in addition to health, cultural, and spiritual reasons (Schenck et al. 2006; van Vliet and Mbazza 2011).

Interventions aimed at changing consumer behavior should be guided by an evidence-informed theory of change (Olmedo et al. 2017). This requires developing an in-depth understanding of why people consume bushmeat when other protein choices are available in urban environments. We address this knowledge gap through an in-depth qualitative approach to investigate socio-cultural drivers of bushmeat demand in Pointe Noire, Republic of Congo. Qualitative research is essential for expanding our understanding of the social aspects of conservation (Drury et al. 2011) as it enables investigation of perceptions and social influences underpinning bushmeat consumption, factors not easily captured through structured survey approaches.

We identify: 1) perceptions of bushmeat and other animal proteins, 2) social norms and the social context associated with bushmeat consumption, and 3) factors limiting or encouraging bushmeat consumption. The role of social norms in influencing bushmeat consumption has rarely been considered (Morsello et al. 2015) yet understanding the perception of norms is essential to devise effective interventions and promote sustainable behavior (McKenzie-Mohr 2011). Here we define social norms as customary rules shaped by how individuals are expected to behave, and how individuals observe others to behave (Cialdini 2003; Bicchieri et al. 2018). Preliminary field-work to inform the construction of the interview guide highlighted that in Pointe Noire bushmeat is perceived as a distinct category of meat. Therefore, we aimed to understand the diversity and complex interplay among social, cultural, and psychological factors underpinning the consumption of bushmeat in general. The insights gained from this study will be useful for conservation practitioners working on the development of behavior change interventions aimed at reducing the consumption of bushmeat among urban residents in Central Africa.

\section{Methods}

\section{Study Location}

Pointe Noire, a city with a population of 969,000 (UN DESA 2015; Fig. 1), is the economic hub of the Republic of Congo and center of the country's petroleum industry. It has seen strong population growth in recent decades (Dorier and Joncheray 2013).
Conservation-focused non-governmental organizations (NGOs) based in Pointe Noire have raised concerns about the extent of bushmeat consumption in the city, which prompted this study.

\section{Data Collection}

We chose a qualitative approach involving guided semistructured interviews. Qualitative approaches focus on obtaining a small set of high-quality in-depth interviews rather than the large sample sizes characteristic of quantitative surveys aimed at producing generalizable observations (Crouch and McKenzie 2006; Moon and Blackman 2014). We chose this approach to explore the complex interplay of perceptions and social influences underpinning bushmeat consumption, factors not easily captured through structured survey approaches yet essential to provide rich contextually explicit knowledge for the development of behavior change campaigns. Unstructured key informant interviews, informal discussions, and two focus group discussions informed the core structure and content of the semi-structured interview guide (Supplementary Materials). Key informants consisted of longterm Pointe Noire residents, including NGO personnel. These individuals were willing to share in-depth perspectives on the consumption of bushmeat in Pointe Noire and later helped to identify people to interview. Informal discussions were held with owners of bushmeat restaurants, and separate focus groups were held with five men and five women of a range of ages and from different districts within the city to get an initial feel for the context of the study.

From May to July 2016, the lead author, initially accompanied by a local research assistant, conducted 30 semistructured interviews with Congolese respondents aged 18 years and over residing in Pointe Noire (Supporting Information). Free Prior Informed Consent (FPIC) was obtained prior to each interview, and respondents were informed that they could stop the interview process at any point. The interview protocol was reviewed and approved by the ethics committee of the Faculty of Natural Sciences, Imperial College London. We obtained a research permit (\#031) from the Institut National de Recherche Forestière (IRF) of the Republic of Congo. Interviews were conducted in French, spoken fluently by all respondents and the research team. We applied care to remain neutral and avoid leading questions and biasing interviews. Follow-up questions were asked during interviews to explore emerging avenues of discussion.

We used convenience and snowball sampling to select respondents (Newing 2010). This involved asking key informants, personal contacts, and respondents to suggest individuals from a variety of different backgrounds who would be willing to participate. We consciously attempted to ensure heterogeneity for age, education, profession, wealth, district of residence, and department of origin to capture individuals from a range of strata in Pointe Noire in order to capture a diversity of 


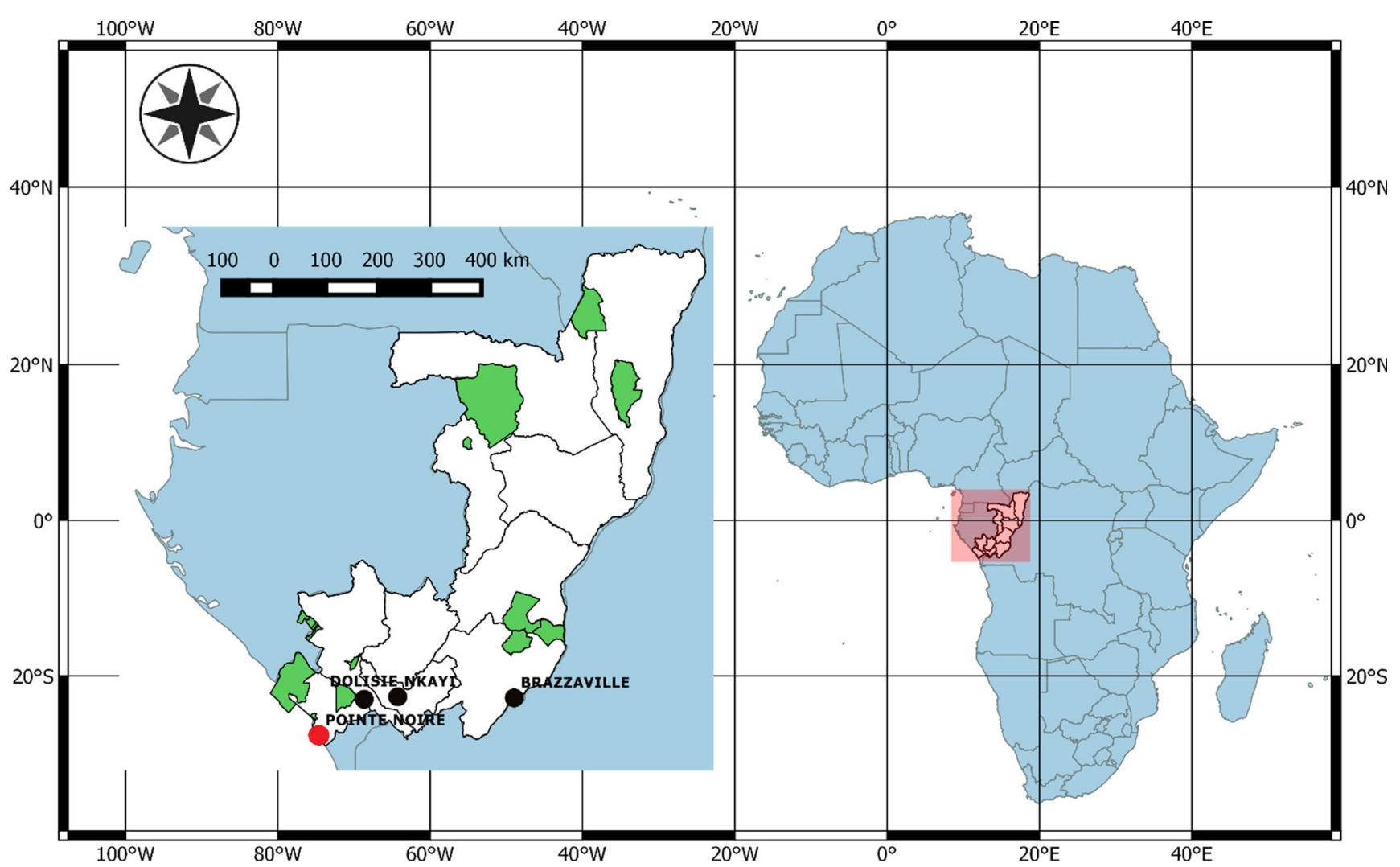

Fig. 1 Map of the Republic of Congo showing Pointe Noire in red, other major cities, protected areas in green, and administrative divisions (departments)

views across socioeconomic backgrounds. A deliberate attempt was also made to balance the gender ratio. We arranged all interviews, apart from one, in advance and conducted interviews in various settings, including respondent households and urban venues with minimal distractions. Interviews ranged in length from 21 minutes to two hours and were concluded when a sense of data richness emerged or due to time restrictions for the respondent. For interviews that were ended prematurely, we arranged a follow-up interview in-person or via telephone. Detailed notes were taken immediately after each interview describing the interview setting, context, and the interviewer-interviewee relationship. Many participants felt uncomfortable being audio recorded, so only eight interviews were recorded with participant consent and later transcribed. For the remaining interviews, the lead author and his assistant took detailed notes with direct quotations. The consumption of bushmeat is not actively controlled in the Republic of Congo, and most respondents appeared comfortable discussing openly their bushmeat consumption. However, in addition to the 30 interviews mentioned, three others were conducted but not analyzed due to reliability concerns since these respondents appeared uncomfortable talking about bushmeat.

\section{Data Coding and Analysis}

Interview transcripts were qualitatively analyzed in NVivo 11.2 (QSR International 2016) through thematic analysis
(Harding 2013). Broad-brush open coding was applied to the first 10 interviews to categorize responses relating to perceptions of bushmeat and other proteins, normative influences on bushmeat consumption, and factors limiting or encouraging bushmeat consumption. The lead author subsequently refined the coding framework to ensure consistency and used this version to code the remaining interviews, remaining flexible for topics and themes not captured in the first 10 interviews. The coding framework was reviewed again postcoding to ensure clear and identifiable distinctions between each code (Braun and Clarke 2006) and that coded data extracts aligned with code definitions. Themes discussed in this paper were mentioned in two or more interviews, following the data reduction approach for qualitative data (Namey et al. 2008). To facilitate analyzing relationships between themes both within and across interviews, the lead author summarized coded data extracts for each respondent using framework matrixes in NVivo. To complement the qualitative analysis, we looked for associations at the individual level between coded perceptions. We tabulated whether each respondent mentioned each perception and calculated the phi coefficient $\varphi$ to measure associations for each pairwise combination of perceptions in R (R Development Core Team 2018). The coefficient ranges from -1 to 1 , where \pm 1 indicates perfect association, and 0 indicates no association (Allen 2017). All pairwise combinations of perceptions not reported in the results are available in the Supplementary Materials. We 
also tabulated the number of respondents expressing each perception to explore within-sample associations among sociodemographic characteristics, bushmeat consumption frequency, and perceptions. However, we intentionally refrain from specifying the number or proportion of respondents expressing particular views in the narrative synthesis as this is not the objective of qualitative inquiry and doing so may be misleading given the low sample size and purposive sampling approach. Importantly, this can distract from the substantive insight that in-depth analyses aim to generate (Patton 2015). To test for bias introduced by including both audio and non-audio transcribed interview transcripts, the lead author plotted the coding output between the two sets $(n=8$ and $n=22$ respectively). The output was proportionally similar suggesting that non-recorded transcripts were reliable (Supplementary Materials). Our approach prioritizes depth of detail from individual respondents over number of respondents and therefore may not provide an exhaustive list of all perceptions, social norms, and other factors influencing bushmeat consumption in Pointe Noire. However, we feel the data still provide new insight into the main drivers of bushmeat demand in urban centers of the Republic of Congo.

\section{Results}

\section{Sample Characterization}

The sample was well balanced with respect to age and education, although most respondents were male (Fig. 2). All but two respondents spent the greater part of their youth in Pointe Noire but traced their roots to eight different regions of the Republic of Congo - Lékoumou, Bouenza, Cuvette, Kouilou, Likouala, Niari, Plateaux, and Pool (Supplementary Materials). In our sample, frequency of bushmeat consumption varied from no consumption in 2016, to several times a week (Fig. 2). Because our sampling approach specifically targeted bushmeat consumers, we expect our sample to reflect higher bushmeat consumption frequencies than found at the city-level.

\section{Bushmeat Consumption}

There was no significant association within the sample between bushmeat consumption frequency and gender, education level, age group, region of origin, or profession (Supplementary Materials). Analyzing the relationship between household wealth and bushmeat consumption frequency was beyond the scope of our study. However, most women reported either not consuming bushmeat, or low levels of consumption (Supplementary Materials; Fig. S2a). Of the five respondents not reporting consumption in 2016, four were women. Most men however reported mid to very high levels of consumption, and most respondents who reported high to very high level of bushmeat consumption were men (at least once a week to several times a week). Just over half of respondents ate bushmeat primarily in the household and the remainder ate primarily in restaurants (formal or informal). We did not aim to determine consumption behavior at the species level, but respondents mentioned consuming a variety of different species, including pangolin, porcupine, cane rat, monkey, wild pig, crocodile, duiker, bushbuck, and tortoise. Some respondents also differentiated between categories of bushmeat such as smoked versus fresh, or 'red' meat (sometimes also referred to as 'black' meat) vs. 'white' meat (i.e., the meat of reptiles and birds). However, bushmeat was salient as a category of its own:

"In general, it's important to know that we are Bantu, we are in the great equatorial forest, bushmeat was our staple food...banana, tarot, and bushmeat" (Respondent 1, 50-year-old male, unemployed engineer).

\section{Perceptions of Bushmeat}

\section{Organic, Natural, Fresh, Healthy, and Local}

The importance of organic, natural, fresh, healthy and local in relation to animal proteins was a prevalent theme (Supplementary Materials). Most respondents perceived bushmeat as meeting these criteria, while also highlighting that it is tasty or appetizing - overall the most prevalent characteristic attributed to bushmeat (Fig. 3a):

"Bushmeat has a different taste to other meats, it's natural, isn't kept in freezers for long periods, and contains a lot of vitamins because it eats all that is natural" (Respondent 13, 36-year-old male, security agent).

The strong taste of bushmeat (smoked or fresh) appears important in part because it removes the need for condiments. Consumers often mentioned taste or health first, but frequently in parallel with perceptions of bushmeat as natural, fresh, or organic and not farmed. Perceptions of bushmeat as tasty were most strongly associated with perceptions of bushmeat as fresh $(\varphi=0.26)$ and local $(\varphi=0.20)$. In turn, the perception of bushmeat as fresh was most strongly associated with the perception of bushmeat as healthy $(\varphi=0.25)$, which was most strongly associated with the perception of bushmeat as natural ( $\varphi=0.33$ ). This supports the notion that these dimensions are interlinked. Wild animals are said to feed on natural, healthy foods that produce nutritious meat high in vitamins that can be eaten fresh locally. These were key characteristics that distinguished bushmeat from human reared meat. 

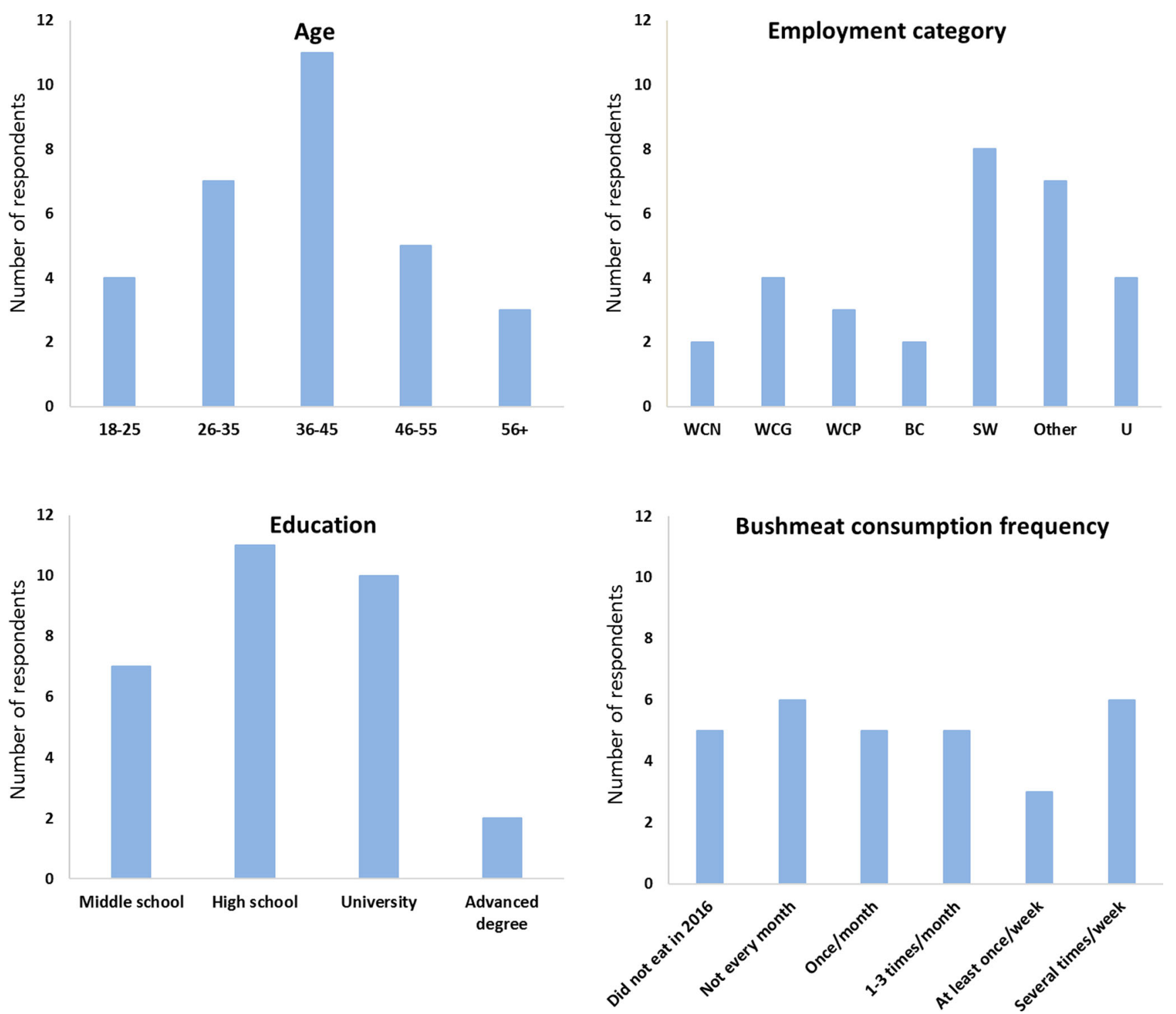

Fig. 2 Socio-economic characteristics of respondents $(n=30)$ and reported bushmeat consumption frequency: a Age category, b Employment category as reported by the respondent $(\mathrm{BC}=$ blue-collar, $\mathrm{SW}=$ service worker, $\mathrm{U}=$ unemployed, $\mathrm{WCN}=$ white-collar non-

When specifically asked why they consumed bushmeat, respondents most frequently cited attributes of natural and fresh (often mentioned together) after taste and cultural influences (i.e., tradition, region of origin, or the influence of village life) (Fig. 3b). Interestingly, younger respondents emphasized the natural and fresh aspects of bushmeat as reasons for their consumption of bushmeat, whereas older respondents emphasized cultural drivers (i.e., tradition, region of origin, or the influence of village life) (Supplementary Materials; Fig. S3b). Only young to middle-aged respondents cited the perception of bushmeat as healthy as a reason for consuming it. Interestingly, only men reported the perception of bushmeat as organic.

governmental organization, $\mathrm{WCG}=$ white-collar government sector, $\mathrm{WCP}=$ white-collar private sector), $\mathbf{c}$ Education level (highest level completed), and d Bushmeat consumption frequency, see Supporting Information for a detailed respondent summary

\section{The Village Environment, Region of Origin, and Cultural Identity}

In parallel with the emphasis on the natural properties and source of bushmeat, the continuing influence of rural village life (i.e., cultural influences) emerged as an important theme and was cited by respondents as a prime driver of bushmeat consumption (Fig. 3b). When explaining why they ate bushmeat, respondents often highlighted growing up eating bushmeat in their village, coming from forested zones where bushmeat is the main staple, or how eating bushmeat is part of their tradition or culture as "Bantu" or "Africans." The link between specific regions of the country and bushmeat consumption, in comparison with the local coastal ethnic group 
Perceptions of bushmeat

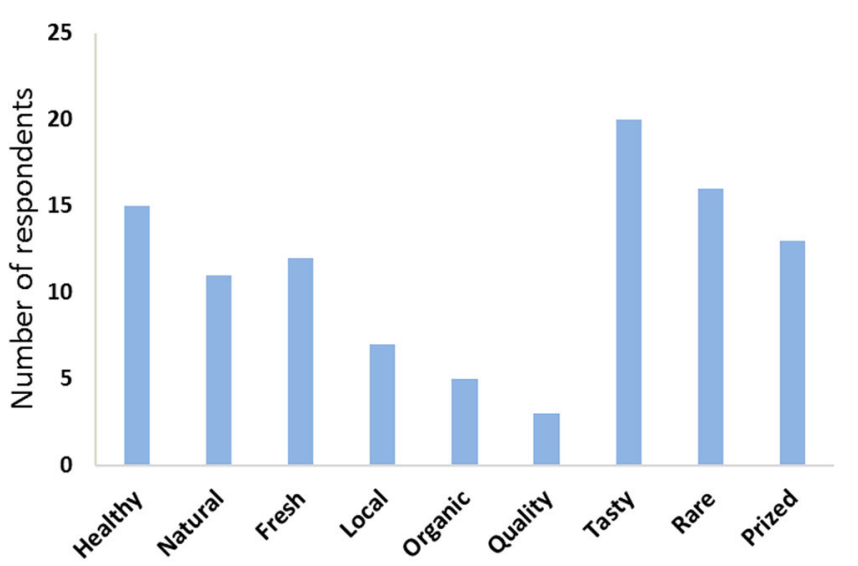

Perceptions frozen imported animal proteins

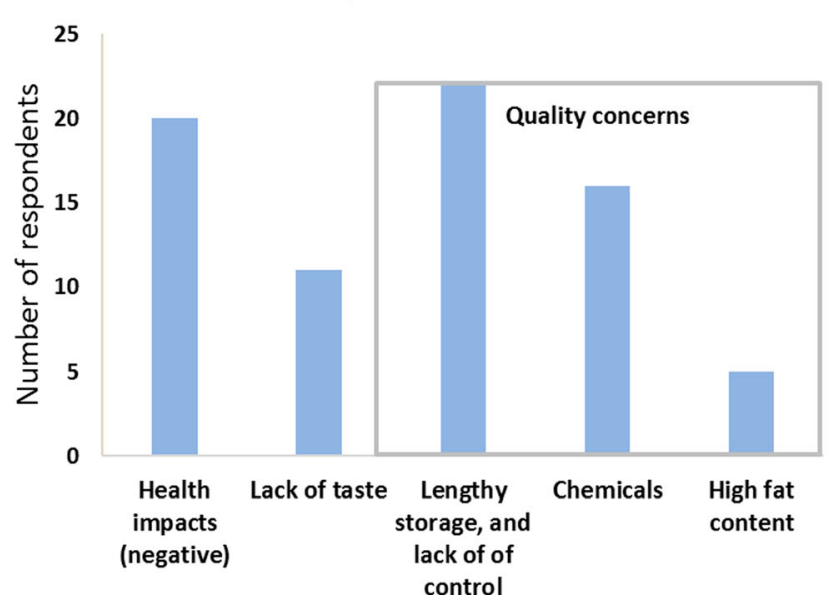

Reasons for consuming bushmeat

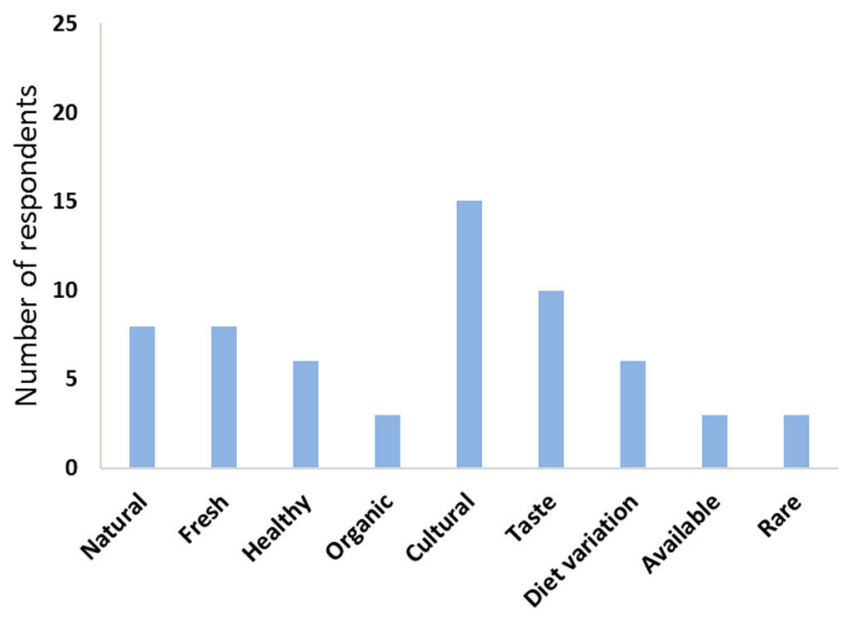

Factors limiting bushmeat consumption

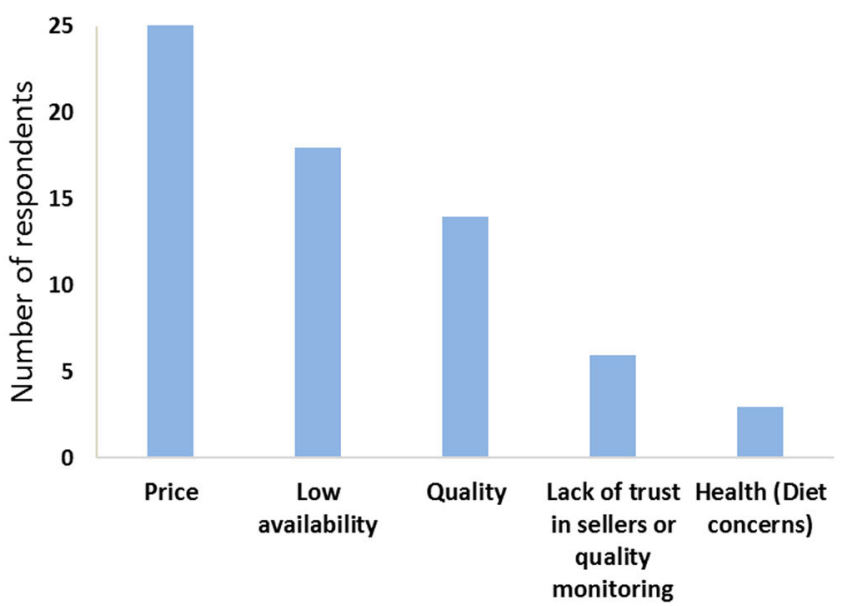

Fig. 3 a Perceptions of bushmeat, $\mathbf{b}$ reasons given for consuming bushmeat, $\mathbf{c}$ perceptions of frozen imported animals, $\mathbf{d}$ factors limiting bushmeat consumption; bars represent the number of respondents reporting each perception. Refer to code book (Appendix S2) for coding definitions

'Vili' who traditionally consume fish, was even emphasized by respondents born in the city. Associations between the traditional consumption of certain species and region were sometimes emphasized. For example, Respondent 6 (small business owner, 53 year-old male), who used to traffic bushmeat to Pointe Noire, stated that: "in the Lékoumou region, monkey meat is particularly appreciated." A few respondents associated the consumption of crocodile meat with the forested districts of the north, such as the Niari, Cuvette, and Plateaux departments. This association holds importance for traditional weddings, for which it is customary for the family of the bride to prepare species traditionally consumed in their region as a gift to the future husband and his family. Some respondents also discussed the pleasure of consuming bushmeat when returning to the village to visit relatives. The taste of bushmeat can bring back memories of the environment in which someone grew up, as highlighted by respondent 18 (31 years old, saleswoman), who stated:

"I like the smoked taste, it reminds me of when I was with my grandmother, it gives it an African touch." Cultural identity therefore appears to be a driver of bushmeat consumption in Pointe Noire.

\section{Bushmeat as Rare, Prized, Luxurious, and Exclusive}

Bushmeat is considered a luxury food, often reported as rare, prized, luxurious, and exclusive (Fig. 3a). Some respondents associated the reported rarity and luxury of bushmeat directly with its perceived natural, organic, and fresh characteristics. Respondent 7 (36-45 years old male, city government official) 
stated that: "people know its importance, its value, because it [bushmeat] is pure, it's natural." This perception of luxury alone also appears to attract people to bushmeat. Some specifically stated that they consume bushmeat "because it is rare" (Respondent 3, 56+ year-old woman, retired). Respondent 7 indicated that bushmeat is not something that everyone gets the opportunity to eat regularly, but "when it's on the table during a festivity, people jump on it." Bushmeat "adds value to an event" (Respondent 14, 34-year-old male, logistician), which reflects social norms influencing bushmeat demand in Pointe Noire.

\section{Social Norms Associated with Bushmeat Demand}

\section{Bushmeat to Please, Honor, Show Appreciation, and Obtain Favors}

The drive to provide and offer bushmeat to important individuals or for special ceremonies appears to be a predominant influence on bushmeat purchasing in Pointe Noire. Bushmeat was perceived as a status symbol and reported to give recognition to the provider and the receiver. "We feel pressured to serve bushmeat because it's precious, ... bushmeat is special and it's not to be eaten everyday" (Respondent 14). "I am proud of eating bushmeat...it's not anyone that eats bushmeat here in Pointe Noire...it's rare in households" (Respondent 30, 43year-old male, unemployed). Serving bushmeat was associated with a desire to please, reward, honor, show appreciation, or obtain favors from important individuals such as partners, parents, close family members or friends, authorities, or influential private or public-sector employees. It was often mentioned that small amounts of bushmeat are reserved for important individuals due to its high price. Respondent 24 (bushmeat vendor, 40 years old) stated that: "many clients buy bushmeat for traditional weddings, funerals, or birthdays." And the important role of bushmeat at such events, including impressing important guests, was reiterated by many respondents. However, other respondents reported not being used to seeing bushmeat at festivities, citing as a reason its high cost.

The perception of bushmeat as a luxury item appears to confer a special status to those who can afford to provide or consume it, thus influencing both purchasing and consumption. Respondent 7 stated that: "in restaurants, when you arrive and ask for a bushmeat dish people look at you. It's exceptional to order bushmeat at a restaurant." In Pointe Noire, bushmeat is often eaten during weekend social gatherings with friends and family members. Just as bushmeat can be used as a gift to obtain favors, it also appears to play an important social function in forging and maintaining relationships; for example, Respondent 18 primarily ate bushmeat in various restaurants where she would meet friends after work. In fact, most young respondents (18-35 years old) ate bushmeat primarily outside of the household, whereas only a few respondents 36 years and older ate primarily in restaurants (Supplementary Materials; Fig. S6). Younger respondents, most of whom did not live with a partner at home, emphasized the social purpose of consuming bushmeat outside of the household to forge relationships. Older respondents are more likely to be married and settled in a household, and therefore more likely to consume bushmeat at home. A few respondents explained that bushmeat is consumed primarily by men while women are more often responsible for preparation. This was sometimes attributed to the legacy of traditional norms that restrict women from the consumption of certain bushmeat species. However, this appears to be changing in Pointe-Noire:

\begin{abstract}
"Among our forefathers, women could not eat certain bushmeat, such as monkey or python...However, with the world that is developing, women now eat it" (Respondent 19, 31-year-old stay-at-home mother).
\end{abstract}

\section{Family Influence}

Of respondents who consumed bushmeat over the last year, half recalled developing the taste for bushmeat during childhood, often stating that their parents influenced their consumption. Some respondents continued to feed, recommend, or want their children to eat bushmeat, either because of its good taste and healthy properties in comparison to frozen animal proteins, or to maintain tradition. However, in light of its high prices, several parents explained that they often feed cheaper frozen meats to their children. Nearly half of respondents, all 36 years or older, mentioned generational variation in food preferences and eating habits with the older generation having a strong preference for bushmeat or fish, while young people growing up in the city do not eat or even like bushmeat:

"The young do not try bushmeat, it's a problem in light of the issues with frozen meats. The young here, they don't want to try [bushmeat] they're not used to it" (Respondent 10, 40-year old, salesman).

They have become accustomed to eating and have developed a taste for frozen meats, including imported chicken, which has become widely available.

Both men and women respondents emphasized that household bushmeat consumption was driven by the male household head, for whom bushmeat was preferentially reserved as a more exclusive or luxurious meat. Of those who can afford to consume bushmeat on a day-to-day basis, it tends to be the male household head requesting it. Respondent 2, a 57-year-old government employee explained: “...I send my wife. It's her that often buys it at my request and sometimes she suggests buying bushmeat knowing that I like to eat bushmeat." 


\section{Factors Limiting Bushmeat Consumption}

\section{Price and Availability}

All respondents, regardless of age or gender, emphasized the high price of bushmeat while explaining that it is reserved for special occasions or important individuals. Price was the most frequently cited barrier to purchasing and consuming bushmeat, followed by low availability, quality, disease, and dietary concerns (Fig. 3d). Four of the five respondents reporting no bushmeat consumption during 2016 cited high prices as the reason. There was no apparent relationship between bushmeat consumption frequency and reported limiting factors (Supplementary Materials). Respondents reported circumventing price barriers in various ways, including buying bushmeat from wholesalers in Pointe Noire or obtaining it outside the city, and eating at cheaper restaurants in lowerincome neighborhoods. Respondents also mentioned that it is possible to buy bushmeat in smaller chopped-up portions according to what one can afford. Price and availability are linked, but price seems to be the main perceived barrier, as one responded commented: "if you have financial means, you can find bushmeat any day" (Respondent 28, 50-year-old male, football coach).

Reduced availability and increasing prices were mentioned by nearly half of respondents, with several attributing this directly to overhunting or animals being "rarer and rarer in the bush" (Respondent 8, 32-year-old male, unemployed). Others attributed lower availability and increased prices to hunting regulations, law enforcement, or conservation measures. However, only one respondent reported reducing their bushmeat consumption because of concern about overhunting.

\section{Disease Risks and Food Safety}

Half of our respondents expressed concerns about contagious diseases and the lack of food safety relating to bushmeat, suggesting that negative perceptions coexist alongside positive perceptions of bushmeat, although the former do not necessarily limit levels of consumption. These concerns were often dependent on the state or source of the bushmeat. For example, several respondents expressed concerns about smoked bushmeat, which they believed to be an inefficient means of preservation, and suspected it was often sold long after slaughter. Yet the same individuals did not express such concerns about fresh bushmeat. Others had concerns about how bushmeat is sold, preferring certain sellers, such as wholesalers at the edge of town with whom they have an established relationship, or specific locations to obtain fresher bushmeat, such as villages outside the city rather than the open-air markets in Pointe Noire. A few, generally older, respondents mentioned concerns about side-effects associated with bushmeat consumption, including that excessive bushmeat consumption can lead to gout, although they associated this exclusively with 'red' bushmeat. Several reported being aware of recommendations to avoid bushmeat due to Ebola outbreaks, but only a few listed concerns over Ebola as a limiting factor, in part because they did not perceive Ebola to be a threat in the Republic of Congo. For example, Respondent 12, a 25-year-old male mechanic who consumes bushmeat at least once a week, reported that people have avoided bushmeat for concerns over Ebola, but stated: "we're lucky that here in Congo [Republic] we didn't really have the epidemic, unlike in neighboring countries where there were many cases."

\section{Law Enforcement}

No respondents were asked about knowledge of the law. However, half expressed awareness of hunting restrictions (seasonal- or species-based), protected areas, or the control of bushmeat transportation:

"When the hunting season is closed it [bushmeat] is more expensive. The transport is exposed to more surveillance by the authorities" (Respondent 23, 36-yearold male, event organizer).

Nearly all these respondents perceived that restrictions increased prices or decreased availability. Eight respondents suggested the regulatory environment is ineffective as bushmeat is still available during the closed hunting season (November 1 to April 30), albeit at a higher price due to bribes reportedly paid to authorities to facilitate transportation. Importantly, no one mentioned legal restrictions associated with bushmeat purchasing. Despite the protected status of some species according to national law, respondents were still happy to discuss consuming species such as pangolin (see Republic of Congo Law No. 37-2008 on Wildlife and Protected Areas).

\section{Perceptions of Other Animal Proteins}

The theme of organic, natural, fresh, and local extended to other animal proteins locally caught or reared and butchered (hereafter referred to as fresh animal proteins). Locally butchered livestock and fish were perceived positively by most respondents who emphasized their "fresh" and "organic" characteristics, with fish often also perceived, like bushmeat, as "natural." Bushmeat consumers perceived fresh animal proteins as healthier and more nutritious because they are not subject to freezing and or other human interference. It is this perception of minimal interference that respondents termed "organic", or "bio" in French, which does not directly map onto the standard definition of "organic" as produced 
without use of artificial chemical fertilizers, pesticides, or other non-organic inputs. The most frequently mentioned "fresh" non-fish animal proteins were locally reared and butchered beef, chicken, and pork. The bushmeat vendor (Respondent 24) explained that some clients state they do not eat frozen meats, and instead look for organic products such as bushmeat, fresh beef, or fresh fish. However, a few respondents expressed concerns over specific production and selling practices, including fish rotting on market stalls having been caught using dynamite, or poor conditions for pigs and other livestock around Pointe Noire.

Respondents reported that the most abundant, affordable, and consumed animal proteins were frozen and imported (hereafter referred to as frozen animal proteins). For example:

“... one portion of bushmeat for 5000 FCFA [8.65

USD] costs the same as buying five days' worth of fro-

zen meat supplies at the market" (Respondent 13, 36-

year-old male, security agent).

However, every respondent but one held negative perceptions of frozen animal proteins (Fig. 3c). There were no apparent associations between reported perceptions and gender, education level, or age, although older $(56+)$ respondents did not mention concerns associated with the high fat content of frozen imported proteins (Supplementary Materials; Fig. S4b).

Frozen animal proteins were said to cause illness and shorten life spans (Fig. 3c). Respondents complained about not knowing where or how the meat was raised and slaughtered, and when and how it was transported and stored, which affected perceptions of quality. The lack of taste of frozen imported meats was a common complaint and was associated with concerns over the quality of frozen imported proteins ( $\varphi=0.34)$ and health consequences stemming from their consumption $(\varphi=0.24)$. Respondents shared their reservations about intensive livestock rearing, with animals subjected to "injections" and "chemicals" creating "artificial" meat. They also mentioned lengthy transport and storage periods, and lack of quality control and safety regulations. In contrast, fresh animal proteins are seen as subjected to less intensive production methods. Many respondents expressed a sense of both hopelessness and helplessness when discussing the reality that households are forced to resort to poor quality meats not subject to rigorous controls to feed themselves because they cannot afford healthier alternatives:

"We are forced to fall back on the frozen [imported meats] to have a reasonable quantity. Otherwise, everybody would prefer to eat fresh meat" (Respondent 26, 51-year-old male, unemployed).

Interestingly, respondents reporting infrequent bushmeat consumption were more vocal about their negative perceptions of frozen imported meats. Respondents stated lack of quality and taste, often in conjunction with negative health impacts in contrast to the positive qualities of fresh animal proteins, including bushmeat. Quality concerns of frozen imported meats were most strongly associated with the perception of bushmeat as natural $(\varphi=0.36)$, followed by healthy $(\varphi=0.29)$. Concerns over lack of taste were most strongly associated with perceptions of bushmeat as fresh ( $\varphi=0.35)$, healthy $(\varphi=0.33)$, and natural $(\varphi=0.27)$.

All respondents reported receiving advice to avoid frozen animal proteins due to the poor quality and negative health impacts, and to eat fresh products. This information came from a variety of sources including the media, schools, medical professionals practicing western medicine, and the public health department through public notices, as well as through friends, relatives, and general word of mouth. Respondent 20, a 45-year-old stay-at-home mother recalled:

"Even on television sometimes, we see how things [frozen imported meats] were thrown away because they were expired... Therefore, it's not good. We must not consume it anymore."

A customs officer confirmed that imports of past sell by-date frozen meats had been intercepted by customs, and that importers regularly try to place spoiled meats for sale on the market (Respondent 29, 47-year-old female). A dietician reported that in medical establishments people are also advised to eat fresh and local products rather than frozen if they can afford to (Respondent 22, 41-year-old female). Respondent 7 stated "In the hospital they recommended she [his sister] eat natural things, and not frozen imported meats in which products are injected and make you sick," subsequently clarifying that "it's necessary to eat bushmeat because it's from the bush, the blood is fresh." The dietician stated that: "fresh meat conserves its nutritional value whereas freezing leads to its degradation." In fact, several respondents emphasized bushmeat as a healthier alternative to frozen animal proteins, and many reported either giving or receiving advice to consume bushmeat for this reason, including Respondent 13 (36year-old male, security agent) who recommended bushmeat consumption to others because: "...when you eat a lot of bushmeat you age more slowly and rarely fall ill.”

\section{Discussion}

The perceptions of bushmeat as a natural, organic, healthy, tasty, luxury product, associated with rarity and high prices, appear to drive its consumption and reinforce the social norm of offering bushmeat to important individuals and on important ceremonial occasions. Our findings corroborate previous studies that have shown bushmeat in central African urban 
areas is considered to be a luxury good (Cowlishaw et al. 2005; Randolph 2016) as well as a healthy, nutritious, and natural food (Kümpel 2006). In Yaoundé, Cameroon, and in Ho Chi Minh City, Vietnam, bushmeat has been shown to signal wealth (Randolph 2016; Shairp et al. 2016). While the luxury perception may be taxon-dependent, as it was in the Yaoundé study, our results suggest that bushmeat in general is considered a luxury. In addition, bushmeat in Pointe Noire contributes to building and maintaining social relationships, as was also shown to be the case in Brazil and Vietnam (Morsello et al. 2015; Shairp et al. 2016). Bushmeat consumption appears to provide strong cultural ties connecting urbanites to their villages and regions of origin (see also van Vliet and Mbazza 2011). Bushmeat consumption forms a part of the cultural identity of those who trace their origins to forested regions. Cultural associations have also been shown to drive bushmeat consumption among urban Amazonians (Morsello et al. 2015), as well as in Bata, Equatorial Guinea, where ethnicity and nationality were found to be key determinants of consumption (East et al. 2005).

East et al. (2005) found that consumers differentiated animal proteins first and foremost by state, with a strong preference for fresh over frozen, as Starkey (2004) also found in Libreville, Gabon. In stark contrast to the positive perceptions of bushmeat, our study also found a widespread disdain towards frozen animal proteins due to negative health outcomes, quality concerns, as well as taste. In Pointe Noire, it appears that positive perceptions associated with the notions of fresh and organic extend beyond bushmeat to other animal proteins, including locally butchered livestock and locally caught fish. We found the health and taste dimensions are interlinked determinants of consumer preference for protein types. Animal proteins subject to limited human interference are considered "organic" and are perceived as fresher, tastier, and healthier. Fish sold fresh and any form of locally butchered meat, including bushmeat, meet this criterion. In contrast, frozen animal proteins are seen as transformed by intensive husbandry, the freezing process, and overly lengthy storage. The disdain towards frozen animal proteins, reinforced by medical, media, and social pressures, coupled with perceptions of bushmeat as tasty and healthy, emerged in this study as key drivers of bushmeat demand.

\section{Implications for Behavior Change}

While it may be tempting to develop a unifying theory of wildlife consumption to inform future management approaches (Brashares et al. 2011), due to the myriad of drivers underlying different people's consumption practices we urge a more nuanced approach. Tackling bushmeat demand will require an in-depth understanding of behaviors and practices specific to an intervention area. Behavior change strategies should always be contextually appropriate.
Deconstructing behavioral complexity is a prerequisite to identifying high-leverage behavior change intervention strategies. Our results show that bushmeat demand is associated with multiple social norms, perceptions, and other drivers. Specific drivers rooted in perceptions and norms should be targeted individually by tailoring messages and identifying the most appropriate channels to communicate these messages to a specific segment of the population (Michie et al. 2011). For example, a strategy aimed at reducing bushmeat provisioning during special occasions, a practice reinforced by the perception of luxury and the desire to please or gain favor, would require a different approach than reducing day-to-day consumption of bushmeat. Our results also suggest that drivers of consumption can vary according to sociodemographic characteristics. For example, younger respondents emphasized the natural, fresh, and healthy aspects of bushmeat, whereas older respondents emphasized cultural connections. City-wide surveys should be conducted to confirm these relationships and tailor messaging to specific segments of the population.

\section{Developing Effective Messages}

Messages must be culturally sensitive to resonate with bushmeat purchasers. Highlighting the negative impacts of a behavior risks reinforcing it if this message clashes with prevailing norms and culture (Schultz 2011; Lertzman and Baragona 2016). Though a substantial proportion of consumers are aware of overhunting, respondents did not indicate any intention to reduce consumption. Raising environmental awareness alone is unlikely to affect demand. High environmental awareness levels and support for environmental protection are often not matched by behavioral changes, usually due to factors perceived to be beyond the individual's control (Kühl et al. 2009; Heberlein 2012). Positive social messages, rather than negative environmental messages, often align better with the priorities of the target audience. For instance, communication targeted at climate change deniers was more effective when the emphasis was placed on improved social welfare outcomes of climate mitigation efforts rather than risks and realities of climate change (Bain et al. 2012). A positive messaging strategy in Pointe Noire could focus on the importance consumers place on the natural sourcing of bushmeat, the forest, to emphasize the benefits provided by forests to people, building pride in this national resource.

Concerns over the quality of bushmeat might indicate an effective means to reduce demand, although it did not appear to limit bushmeat consumption for most respondents, who instead cited price as the limiting factor. For some, this was because they could procure bushmeat fresh or from trusted sellers. The health impacts our respondents associated with 
frozen animal proteins show that consumers are cognizant of their eating habits in relation to health, or more importantly what they perceive to be healthy. Interventions could highlight the negative health impacts of bushmeat overconsumption (e.g., gout), which some respondents and the dietician (Respondent 22), were concerned about. In Yaoundé, this was the reason most frequently given for stopping bushmeat consumption (Randolph 2016). Campaign strategies should not use zoonotic disease threats from bushmeat consumption for conservation purposes as this could have unintended repercussions, such as eradication of disease vectors or undermining confidence in the campaign among consumers who do not perceive disease to be a threat in the region (Pooley et al. 2015).

\section{Harnessing the Support of Local Actors and Institutions}

The reach and uptake of a message is heavily dependent on who presents it (McKenzie-Mohr 2011), so that harnessing the support of locally influential figures and institutions as messengers to change perceptions and beliefs could be an effective way to bring about behavior change. For example, in Central Africa, including in the Republic of Congo, faith leaders are socially and politically very influential, particularly with the growing influence of Protestant groups (Fath and Mayrargue 2014). Since bushmeat consumption is customary on weekends, messages disseminated during Sunday worship could be effective. Our findings do not quantify the extent to which medical professionals or the media specifically promote bushmeat consumption when advising people to avoid frozen animal proteins. However, these actors clearly exert an important influence on dietary choices and may indirectly incite consumers to turn towards bushmeat through their advice. Interventions could potentially involve these actors to ensure they avoid promoting bushmeat demand.

We found bushmeat consumption is a customary practice in Pointe Noire. Structural elements and systemic influences that maintain the practice, such as informal and formal restaurants selling bushmeat, should also be targeted (Shove 2010). Without complementary actions tackling systemic elements driving bushmeat consumption, behavior change interventions may fall short of their goals. Therefore, in addition to intervention strategies designed to target individual bushmeat consumers, infrastructural elements that sustain bushmeat consumption also need to be targeted where possible. For example, restaurants could be targeted to promote nonbushmeat dishes, thus supporting messaging aimed at consumers themselves. Similarly, establishments, such as hotels or private companies that facilitate consumption by providing bushmeat to their guests and employees for special events, as reported by Respondent 27, a hotel employee, could be targeted.

\section{Facilitating a Product Switch}

Changing bushmeat consumption behavior implies consumers will turn towards other protein sources. Interventions should combine messages about bushmeat with a careful attempt to harness positive perceptions associated with other protein sources to encourage consumers to switch. Understanding perceptions and social norms associated with other animal proteins can provide insight into necessary attributes of substitutable alternatives. Because they are affordable, frozen animal proteins are already consumed in large quantities in Central Africa (Nasi et al. 2011), but there is also widespread disdain towards frozen animal proteins, to a large extent driven by what appear to be serious product quality issues that would need to be addressed. The well-being of people targeted by behavior change interventions should remain a core focus of any strategy. Therefore, any promotion of alternatives to bushmeat would likely be more effective if it concentrated on local fish, livestock, and poultry, which consumers perceive more positively.

Respondent statements highlighted a potential Veblen effect driving bushmeat consumption, whereby the conspicuous consumption of bushmeat acts as a status symbol because of its high price (Bagwell and Bernheim 1996). Therefore, consumers are more likely to switch to prized local fresh meats such as beef or expensive fish. Positive perceptions attributed to fresh fish among bushmeat consumers and evidence for economic substitution of fish and bushmeat in similar urban coastal contexts would suggest that fish protein might be a promising alternative (Brashares 2004). However, perceptions attributed to bushmeat and other available animal proteins may not be static. That younger people are reported to be more accepting of frozen animal proteins is potentially promising for reduced bushmeat consumption in future. Yet it is unclear how this will play out, since general distain for frozen meat in parallel with bushmeat being perceived positively could influence the dietary habits of younger generations as they exit the household. Introducing environmental education activities in schools to raise awareness of urban bushmeat consumption impacts could be crafted to preemptively counter social pressures promoting bushmeat consumption.

In addition to institutional and economic barriers to the intensification of livestock production (McDermott et al. 2010), the impacts of substituting bushmeat with local livestock, poultry, or fish can present new problems. Fish stocks are depleted regionally (Polidoro et al. 2017) and increasing livestock or poultry production, or promoting aquaculture, would be associated with increasing land development pressures and negative environmental impacts (Poore and Nemecek 2018). Therefore, intervening actors should responsibly investigate potential unintended outcomes of their approach. 
In attempting to address urban bushmeat demand, conservationists are intervening in a complex social-ecological system involving many relationships and different perspectives (Ulrich and Reynolds 2010). In this context, successful interventions depend on considering the perspectives of all actors (Cook et al. 2013). Importantly, implementing organizations should always consider the extent and nature of potential social impacts stemming from intervention (Woodhouse et al. 2016). This initial baseline study provides a qualitative understanding of behavioral and contextual influences shaping urban bushmeat demand in a context where other animal proteins are available, and can help guide conservation and development practitioners designing and implementing interventions aimed at changing consumer behavior in Central Africa. Our findings also illustrate how practitioners should consider the potential limitations of behavior change interventions to identify what complementary actions may be needed to effect the desired change, such as tackling systemic elements driving consumption. We hope our findings will spur further research on the socio-cultural underpinnings of bushmeat consumption to enable cross-context comparisons. Our results can inform further data collection and support evidence-informed theories of change to develop effective demand-reduction interventions. Further research is needed to establish the prevalence of specific perceptions, social norms, and how they vary by socioeconomic and psychosocial parameters, as well as between different species consumed as bushmeat.

Acknowledgements We thank YoYo Communications, A. Sitou from the Jane Goodall Institute in Pointe Noire, and N. Gami at the Wildlife Conservation Society in Brazzaville for their generous guidance throughout the course of our field-work. We also thank J. Mavoungou for his assistance with the interview process, and A. Knight at Imperial College London for his guidance and helpful comments on a previous draft. This study was made possible by the support of the United States Agency for International Development (USAID) and the United States Fish and Wildlife Service (USFWS). The contents of this paper are the sole responsibility of the authors and do not necessarily reflect the views of USAID or the United States Government. A.M.C. was also supported by a bursary from Imperial College London.

Data Availability Statement The data that support the findings of this study are available from the Wildlife Conservation Society but restrictions apply to the availability of these data, which were used under license for the current study, and so are not publicly available. Data are however available from the authors upon reasonable request and with permission of the Wildlife Conservation Society.

Funding This study was funded by the United States Fish and Wildlife Service (F15AP00735) for the project 'Reducing threats to wildlife from urban bushmeat demand' and USAID (\#AID-660-A-13-00003) for implementation of the 'Central Africa Forest Ecosystems Conservation (CAFEC) - Bateke-Leconi-Lefini Forest Landscape.'

\section{Compliance with Ethical Standards}

Conflict of Interest The authors declare no potential conflicts of interest with respect to the research, authorship, and/or publication of this article.
Open Access This article is distributed under the terms of the Creative Commons Attribution 4.0 International License (http:// creativecommons.org/licenses/by/4.0/), which permits unrestricted use, distribution, and reproduction in any medium, provided you give appropriate credit to the original author(s) and the source, provide a link to the Creative Commons license, and indicate if changes were made.

\section{References}

Allen, M. ed. (2017). The SAGE encyclopedia of communication research methods. SAGE Publications.

Bagwell, L. S., and Bernheim, B. D. (1996). Veblen effects in a theory of conspicuous consumption. The American Economic Review 86(3): 349-373.

Bain, P. G., Hornsey, M. J., Bongiorno, R., and Jeffries, C. (2012). Promoting pro-environmental action in climate change deniers. Nature Climate Change 2(8): 600.

Bicchieri C., Muldoon R., and Sontuoso A. (2018). Social Norms. The Stanford Encyclopedia of Philosophy (Winter 2018 Edition). Zalta E. N. editors. Available from https://plato.stanford.edu/cgi-bin/ encyclopedia/archinfo.cgi?entry=social-norms. Accessed February 2019.

Brashares J.S. (2004). Bushmeat Hunting, Wildlife Declines, and Fish Supply in West Africa. Science 306(5699): 1180-1183. https://doi. org/10.1126/science.1102425.

Brashares, J. S., Golden, C. D., Weinbaum, K. Z., Barrett, C. D. B., and Okello, G. V. (2011). Economic and geographic drivers of wildlife consumption in rural Africa. Proceedings of the National Academy of Sciences of the United States of America 108(34): 13931-13936.

Braun, V., and Clarke, V. (2006). Using thematic analysis in psychology. Qualitative research in psychology 3(2): 77-101.

Cialdini, R. B. (2003). Crafting normative messages to protect the environment. Current directions in psychological science 12(4): 105109.

Cook, C. N., Mascia, M. B., Schwartz, M. W., Possingham, H. P., and Fuller, R. A. (2013). Achieving conservation science that bridges the knowledge-action boundary. Conservation Biology 27(4): 669678.

Cowlishaw, G., Mendelson, S., and Rowcliffe, J. M. (2005). Evidence for post-depletion sustainability in a mature bushmeat market. Journal of Applied Ecology 42(3): 460-468.

Crouch, M., and McKenzie, H. (2006). The logic of small samples in interview-based qualitative research. Social science information 45(4): 483-499.

de Merode, E., and Cowlishaw, G. (2006). Species protection, the changing informal economy, and the politics of access to the bushmeat trade in the Democratic Republic of Congo. Conservation Biology 20(4): 1262-1271.

Dorier E., and Joncheray M. (2013). Territoires fragmentés et temporalités postconflit: décomposition et recompositions territoriales entre guerre et paix en République du Congo. Sortir de la guerre, éditions du CTHS, Paris. 113-126.

Drury, R., Homewood, K., and Randall, S. (2011). Less is more: The potential of qualitative approaches in conservation research. Animal Conservation 14(1): 18-24.

East, T., Kümpel, N. F., Milner-Gulland, E. J., and Rowcliffe, J. M. (2005). Determinants of urban bushmeat consumption in Rio muni, Equatorial Guinea. Biological Conservation 126(2): 206-215.

Effiom, E. O., Nunez-Iturri, G., Smith, H. G., Ottosson, U., and Olsson, O. (2013). Bushmeat hunting changes regeneration of African 
rainforests. Proceedings of the Royal Society of London B 280(1759): 20130246.

Fath, S., and Mayrargue, C. (2014). Les nouveaux christianismes en Afrique. Afrique contemporaine (4): 13-26.

Golden, C. D., Fernald, L. C., Brashares, J. S., Rasolofoniaina, B. J., and Kremen, C. (2011). Benefits of wildlife consumption to child nutrition in a biodiversity hotspot. Proceedings of the National Academy of Sciences of the United States of America 108(49): 19653-19656.

Harding, J. (2013). Qualitative data analysis from start to finish, Sage, London.

Heberlein, T. A. (2012). Navigating environmental attitudes. Conservation Biology 26(4): 583-585.

Kühl, A., Balinova, N., Bykova, E., Arylov, Y. N., Esipov, A., Lushchekina, A. A., and Milner-Gulland, E. J. (2009). The role of saiga poaching in rural communities: Linkages between attitudes, socio-economic circumstances and behaviour. Biological Conservation 142(7): 1442-1449.

Kümpel N.F. (2006). Incentives for sustainable hunting of bushmeat in Río Muni, Equatorial Guinea. Doctoral dissertation. Zoological Society of London and Imperial College London, University of London. 247 p. Available from https://www.iccs.org.uk/wpcontent/thesis/KumpelPhD.pdf (accessed July 2017).

Lertzman, R., and Baragona, K. (2016). Reducing desire for ivory: A psychosocial guide to address ivory consumption, World Wildlife Fund, Gland.

McDermott, J. J., Staal, S. J., Freeman, H. A., Herrero, M., and Van de Steeg, J. A. (2010). Sustaining intensification of smallholder livestock systems in the tropics. Livestock science 130(1-3): 95-109.

McKenzie-Mohr, D. (2011). Fostering sustainable behavior: An introduction to community-based social marketing, 3th edn., New Society Publishers, Gabriola Island.

Michie S., van Stralen M.M., and West R. 2011. The behaviour change wheel: A new method for characterising and designing behaviour change interventions. Implementation Science 6(1):1.

Moon, K., and Blackman, D. (2014). A guide to understanding social science research for natural scientists. Conservation Biology 28: 1167-1177.

Morsello C., Yagüe B., Beltreschi L., Van Vliet N., Adams C., Schor T., Quiceno-Mesa M.P., and Cruz D. 2015. Cultural attitudes are stronger predictors of bushmeat consumption and preference than economic factors among urban Amazonians from Brazil and Colombia. Ecology and Society 20(4):21. DOI: https://doi.org/10.5751/ES07771-200421

Namey, E., Guest, G., Thairu, L., and Johnson, L. (2008). Data reduction techniques for large qualitative data sets. Handbook for team-based qualitative research 2(1): 137-161.

Nasi, R., Taber, A., and van Vliet, N. (2011). Empty forests, empty stomachs? Bushmeat and livelihoods in the Congo and Amazon basins. International Forestry Review 13(3): 355-368.

Newing, H. (2010). Conducting research in conservation: Social science methods and practice, Routledge, London.

NVivo qualitative data analysis Software; QSR International Pty Ltd. Version 11.2, 2016.

Olmedo A., Sharif V., and Milner-Gulland E.J. (2017). Evaluating the design of behaviour change interventions: A case study of rhino horn in Vietnam. Conservation Letters https://doi.org/10.1111/conl. 12365.

Patton, M. Q. (2015). Qualitative Research \& Evaluation Methods: Integrating theory and practice, 4th edn., Sage, Thousand Oaks.

Peres, C. A., Emilio, T., Schietti, J., Desmouliere, S. J., and Levi, T. (2016). Dispersal limitation induces long-term biomass collapse in overhunted Amazonian forests. Proceedings of the National
Academy of Sciences of the United States of America 113(4): 892-897.

Polidoro, B. A., Ralph, G. M., Strongin, K., Harvey, M., Carpenter, K. E., Arnold, R., Buchanan, J. R., Camara, K. M. A., Collette, B. B., and Comeros-Raynal, M. T. (2017). The status of marine biodiversity in the eastern Central Atlantic (West and Central Africa). Aquatic Conservation: Marine and Freshwater Ecosystems 27(5): 10211034.

Pooley, S., Fa, J. E., and Nasi, R. (2015). No conservation silver lining to Ebola. Conservation Biology 29(3): 965-967.

Poore, J., and Nemecek, T. (2018). Reducing food's environmental impacts through producers and consumers. Science 360(6392): 987 992.

R Core Team (2018). R: A language and environment for statistical computing. R Foundation for statistical computing, Vienna, Austria. URL https://www.R-project.org/.

Randolph S. (2016). The social, economic and cultural dimensions of bushmeat in Yaoundé, Cameroon. Doctoral dissertation. Stanford University. Available from https://searchworks.stanford.edu/view/ 11607361 (accessed July 2017)

Rowcliffe, J. M., de Merode, E., and Cowlishaw, G. (2004). Do wildlife laws work? Species protection and the application of a prey choice model to poaching decisions. Proceedings of the Royal Society of London 271(1557): 2631-2636.

Schenck, M., Nsame Effa, E., Starkey, M., Wilkie, D., Abernethy, K., Telfer, P., Godoy, R., and Treves, A. (2006). Why people eat bushmeat: Results from two-choice, taste tests in Gabon, Central Africa. Human Ecology 34(3): 433-445.

Schultz, P. (2011). Conservation means behavior. Conservation Biology 25(6): 1080-1083.

Shairp, R., Veríssimo, D., Fraser, I., Challender, D., and MacMillan, D. (2016). Understanding urban demand for wild meat in Vietnam: Implications for conservation actions. PloS ONE: e0134787. https://doi.org/10.1371/journal.pone.0134787.

Shove, E. (2010). Beyond the ABC: Climate change policy and theories of social change. Environment and Planning A 42(6): 1273-1285.

Somorin, O. A., Brown, H. C. P., Visseren-Hamakers, I. J., Sonwa, D. J., Arts, B., and Nkem, J. (2012). The Congo Basin forests in a changing climate: Policy discourses on adaptation and mitigation (REDD). Global Environmental Change 22(1): 288-298.

Starkey M.P. (2004). Commerce and subsistence: The hunting, sale and consumption of bushmeat in Gabon. Doctoral dissertation. University of Cambridge. Available from https://www.repository. cam.ac.uk/handle/1810/251940 (accessed July 2017).

Ulrich W., and Reynolds M. (2010). Critical systems heuristics. Pages 243-292 systems approaches to managing change: A practical guide. Springer Science \& Business Media.

UN DESA. (2015). World urbanization prospects: The 2014 revision. New York.

van Vliet, N., and Mbazza, P. (2011). Recognizing the multiple reasons for bushmeat consumption in urban areas: A necessary step toward the sustainable use of wildlife for food in Central Africa. Human Dimensions of Wildlife 16: 45-54.

Wilkie, D.S., Starkey, M., Abernethy, K., Effa, E.N., Telfer, P. and Godoy, R. (2005). Role of Prices and Wealth in Consumer Demand for Bushmeat in Gabon, Central Africa. Conservation Biology 19(1): 268-274.

Woodhouse E., de Lange E., Milner-Gulland E.J. (2016) Evaluating the impacts of conservation interventions on human wellbeing. Guidance for practitioners. IIED, London

Publisher's Note Springer Nature remains neutral with regard to juris dictional claims in published maps and institutional affiliations. 